\title{
Social and Health Status of Community-Dwelling Older Adults in Nepal
}

\author{
Hom Nath Chalise ${ }^{1 *}$, Edwin Rosenberg² \\ ${ }^{1}$ Population Association of Nepal, Kathmandu, Nepal \\ ${ }^{2}$ Department of Sociology, Appalachian State University, Boone, NC, USA \\ Email: chalisehkpp@gmail.com, rosenberge@appstate.edu
}

How to cite this paper: Chalise, H.N. and Rosenberg, E. (2019) Social and Health Status of Community-Dwelling Older Adults in Nepal. Advances in Aging Research, 8, 63-74.

https://doi.org/10.4236/aar.2019.84005

Received: June 20, 2019

Accepted: July 28, 2019

Published: July 31, 2019

Copyright () 2019 by author(s) and Scientific Research Publishing Inc. This work is licensed under the Creative Commons Attribution International License (CC BY 4.0).

http://creativecommons.org/licenses/by/4.0/

(c) (i) Open Access

\begin{abstract}
Background: Most developing countries are ageing at unprecedented rates, yet they are relatively under-studied regarding the demographic and health status of the older population. This in turn inhibits appropriate, positive societal responses. This study presents the socio-demographic and health status of older adults in Nepal. Methods: This study is a secondary analysis of structured interview data collected by the Central Department of Population Studies at Tribhuvan University (TU) via a cross-sectional survey of community-dwelling persons age 60+ in the Pharping area of Kathmandu. For this study, there were 1326 valid responses. Results: Respondents' mean age was 69.92 years $(\mathrm{sd}=$ $7.82)$. The majority $(70 \%)$ was illiterate. Nearly $3 / 5$ of women were widowed (58.4\%), which nearly doubles the male rate (31.8\%). Over three-quarters of respondents $(78.6 \%)$ were living with family members, far more than with spouse only (11.6\%), alone (6.2\%) or with others (3.6\%). Only $9.2 \%$ of respondents received a pension, and over seventy percent of respondents (70.7\%) were still working. About three-quarters (76.5\%) of respondents had physical health problems; $14.6 \%$ had some physical disability, and $52.6 \%$ self-reported a mental health problem. Statistically significant $(\mathrm{p}<0.01)$ gender differences were found for marital status, literacy, living arrangements, pensions, physical health problems, and mental health problems. Conclusions: Like most nations, Nepal is ageing rapidly. There are gender differences that can differentially affect the experiences of older men and women. Nepal should increase the quantity and quality of data describing its older population so it can continue to develop appropriate, effective social and health programs and services to reduce gender disparities and maximize elderly quality of life.
\end{abstract}

\section{Keywords}

Ageing, Health, Gender, Nepal

${ }^{\star}$ Dr. Chalise is Vice President of the Population Association of Nepal. In Summer 2019 he was a visiting researcher at Appalachian State University. 


\section{Background}

The world's population is ageing rapidly. The proportion of people age $60+$ will double between 2000 and 2050, from about $11 \%$ to $22 \%$ [1]. Populations are also ageing rapidly in less developed regions. From 2020-2060 the proportion of older adults in these regions is predicted to nearly double from 11.9 percent to 21.8 percent [2]. Thus population ageing is ubiquitous, regardless of a nation's level of development [3]. Ageing has direct and indirect implications for families, health and economics at both micro and macro levels [1]. However, such issues remain relatively under-researched, particularly in poorer and developing countries. Consequently, there is a dearth of specific initiatives in such nations for developing programs and services to enhance the well-being and quality of life of the older population [4].

One feature of ageing populations is increased longevity. Rising life expectancy brings both societal opportunities and societal challenges [5], including changes in family structure and dynamics [6], living arrangements, marital status, and care and support for the elderly [6] [7]. In Nepal, persons age 60+ are considered elderly [8] and constitute $8.13 \%$ of the total population [9]. Nepalese life expectancy, which was 54 years in 1991 [10], is now 71 years [11], an increase of more than one-half year annually [12].

Nearly all elderly Nepalese, whether individuals or couples, live with their children; previous studies found more than $85 \%$ living with non-spouse (as well as spouse) family members [3] [10] [13] [14] [15]. Caring for one's parents-one dimension of filial piety-is considered a duty of adult children [3]; government historically had little obligation to provide care for the elderly [7] [13]. However, recent demographic and socio-economic changes, such as the rapid increase of the older population and the out-migration of children from rural areas, have led to changes in the traditional care system [16]. One example is a rise in the number of elderly living in old age homes [17] [18].

An examination of older adults' social and health status issues, whether at micro or macro levels, cannot ignore the impact of gender. Various studies show gender to be an important variable in this line of inquiry (e.g. [3] [19] [20]). Researchers and agencies such as the World Health Organization argue that "to fully understand ageing and health a gender perspective is required" [21].

The demographic transition, effected by falling mortality and fertility, results in an ageing society. Developing and, especially, least developed nations experience a concomitant epidemiologic transition, as the major causes of death shift from infectious, communicable diseases to chronic, non-communicable diseases like heart disease, cancer and diabetes [22]. Relatively little, however, is known about the health status of older populations in poorer developing countries. Available databases are less complete and more recently developed, hindering longitudinal analysis, and governments place less priority on the issues of older adults due to the historical, dominant role of families in caring for their elderly [3]. The economic, social and health status of Nepalese elderly are, 
however, increasingly important social concerns because, as in many other developing countries, Nepal's older population is growing rapidly while there is no well-developed old age pension (social security) system [16]. The objective of this paper is to explore the social and health traits of community-dwelling older adults in Nepal in order to identify key gerontological issues of elderly well-being and quality of life.

\section{Methods}

This research is a secondary analysis of cross-sectional data from a survey conducted by Tribhuvan University's (TU) Central Department of Population Studies (CDPS) in six Village Development Committees (VDCs) of the Pharping area in Kathmandu, Nepal [23]. VDCs are lower-level administrative areas; Nepal had over 3200 of them at the time of the survey [24]. The VDCs in this study were a convenience sample, as they comprise the catchment area of one community hospital in Pharping. Each VDC has nine wards (the lowest-level political unit). This yielded 54 wards, which were considered the Primary Sampling Units (PSUs) for this study.

For each ward, and with the help of the VDC office and community leaders, a list of all households was developed. Random sampling was applied to each ward's list and continued until the goal of 20 households with at least one member age 60+ was reached. This yielded 1080 households, of which 1070 (99\%) consented to interviews. All persons age 60+ years in each household were interviewed. Of the 1375 older adults in the 1070 consenting households, 1355 (98.5\%) consented to be interviewed. For the purpose of this study, people who reported clinical diagnosis of Alzheimer's disease or another dementia were excluded, as were those for whom some demographic data were missing; there were 29 such cases. Thus the total sample size for this analysis was 1326 older adults.

Interviews were conducted using a structured questionnaire containing demographic, social, economic and health related information. SPSS version 20 was used to analyze the data. Chi-square assessed male-female differences for selected variables, using $\mathrm{p}<0.01$ to indicate a significant difference.

This study was approved by the Nepal Health Research Council (Ref No. 211, Reg No. 66/2012) as conforming to ethical research standards. Training for the thirteen field researchers/surveyors included not only research ethics such as voluntary participation, informed consent and identity protection, but also techniques for effectively interviewing older persons. It was emphasized that elderly respondents be treated with respect, dignity and honor. Direct or indirect discrimination based on age, gender, social and economic class, disability/health status, and residence during the interview process would not be tolerated. For each participant, verbal informed consent was obtained before beginning the interview. Verbal informed consent is very common in such studies [3] [15] as it is not unusual for a majority of respondents to be illiterate. 


\section{Results}

Respondents' age ranged from 60 to 99 years $(69.92 \pm 7.82)$. Half of the respondents were female (50.5\%). The majority (70\%) were illiterate, with women significantly more so than men $(\mathrm{p}=0.000)$. Nearly half $(45.2 \%)$ were widowed; widowhood was significantly more common among women $(\mathrm{p}=0.000)$. More than three-fourths (78.6\%) were living with family members; only about one in ten (11.6\%) lived with spouse only. Seven in 10 (70.7\%) were still working formally (for pay) or informally (unpaid household or family agricultural work). Less than one in ten $(9.2 \%)$ was receiving a pension; pensioners were significantly more likely to be male $(\mathrm{p}=0.008)$. These results are shown in Table 1 .

Table 1. Socio-demographic characteristics of the sample.

\begin{tabular}{|c|c|c|c|c|c|c|}
\hline \multirow{2}{*}{ Variables } & \multicolumn{2}{|c|}{ Male } & \multicolumn{2}{|c|}{ Female } & \multirow{2}{*}{$\begin{array}{c}\text { Total } \\
\%\end{array}$} & \multirow{2}{*}{$\begin{array}{l}\text { Chi-square for } \\
\text { sex differences }\end{array}$} \\
\hline & Number & Percent & Number & Percent & & \\
\hline Age & & & & & & 0.018 \\
\hline $60-64$ & 210 & 32.0 & 185 & 27.7 & 29.8 & \\
\hline $65-69$ & 175 & 26.6 & 186 & 27.8 & 27.2 & \\
\hline $70-74$ & 107 & 16.3 & 98 & 14.6 & 15.5 & \\
\hline $75-79$ & 90 & 13.7 & 105 & 15.7 & 14.7 & \\
\hline $80+$ & 75 & 11.4 & 95 & 14.2 & 12.8 & \\
\hline \multicolumn{7}{|l|}{ Sex } \\
\hline Male & 657 & 49.5 & 669 & 50.5 & & \\
\hline Marital status & & & & & & $0.000^{*}$ \\
\hline Married & 423 & 64.4 & 255 & 38.1 & 51.1 & \\
\hline Widow/widower & 209 & 31.8 & 391 & 58.4 & 45.2 & \\
\hline Others $^{1}$ & 25 & 3.8 & 23 & 3.4 & 3.7 & \\
\hline Literacy status & & & & & & $0.000^{*}$ \\
\hline Literate & 355 & 54.0 & 43 & 6.4 & 30.0 & \\
\hline Illiterate & 302 & 46.0 & 626 & 93.6 & & \\
\hline Living arrangement & & & & & & $0.000^{*}$ \\
\hline Family members & 498 & 75.9 & 544 & 81.3 & 78.6 & \\
\hline Spouse only & 97 & 14.8 & 57 & 8.5 & 11.6 & \\
\hline Alone & 31 & 4.7 & 51 & 7.5 & 6.2 & \\
\hline Others $^{2}$ & 30 & 4.6 & 17 & 2.5 & 3.5 & \\
\hline Working status & & & & & & 0.818 \\
\hline Working & 467 & 71.2 & 471 & 70.6 & 70.7 & \\
\hline Pension status & & & & & & $0.008^{*}$ \\
\hline Receiving pension & 117 & 17.8 & 5 & 0.7 & 9.2 & \\
\hline
\end{tabular}

${ }^{1}$ Includes unmarried, divorced and separated. ${ }^{2}$ Other: brother/sister-in-law, neighbors, etc. ${ }^{*} \mathrm{p}<0.01$. 
Table 2 shows three dimensions of self-reported health status of the community-dwelling respondents. Overall, three-quarters (76.5\%) reported at least one physical health problem, with females significantly more likely $(p=0.005)$ than males to self-report health problems. The most commonly-mentioned physical health problems of the sample of older adults were physical pain (60.4\%), respiratory problems (38.4\%), gastritis (34.4\%), eye problems (29.4\%), blood pressure $(21.8 \%)$ and dental problems (20.4\%). About one in 10 (13.7\%) reported some type of dementia that had not yet been clinically diagnosed. Less than 10 percent

Table 2. Self-reported health status of community living older adults.

\begin{tabular}{|c|c|c|c|c|c|c|}
\hline \multirow{2}{*}{ Health Status } & \multicolumn{2}{|c|}{ Male } & \multicolumn{2}{|c|}{ Female } & \multirow{2}{*}{$\begin{array}{c}\text { Total } \\
\%\end{array}$} & \multirow{2}{*}{$\begin{array}{c}\text { Chi-square for } \\
\text { male-female } \\
\text { differences }\end{array}$} \\
\hline & Number & Percent & Number & Percent & & \\
\hline Physical health problem & 481 & 73.2 & 534 & 79.8 & 76.5 & $0.005^{*}$ \\
\hline Physical pain & 281 & 58.3 & 333 & 62.4 & 60.4 & 0.656 \\
\hline Respiratory problem & 186 & 38.7 & 204 & 38.2 & 38.4 & 0.879 \\
\hline Blood pressure & 102 & 21.2 & 119 & 22.3 & 21.8 & 0.678 \\
\hline Diabetes & 34 & 7.1 & 38 & 7.1 & 7.1 & 0.977 \\
\hline Gastritis & 142 & 29.5 & 207 & 38.8 & 34.4 & $0.002^{*}$ \\
\hline Asthma & 34 & 7.1 & 51 & 9.6 & 8.4 & 0.154 \\
\hline Heart & 22 & 4.6 & 38 & 7.1 & 5.9 & 0.086 \\
\hline Teeth & 100 & 20.8 & 107 & 20.0 & 20.4 & 0.766 \\
\hline Eye & 142 & 29.5 & 156 & 29.2 & 29.4 & 0.914 \\
\hline Kidney/urinary & 38 & 7.9 & 28 & 5.2 & 6.5 & 0.087 \\
\hline Uric acid & 29 & 6.0 & 17 & 3.2 & 4.5 & 0.030 \\
\hline Dementia/Alzheimer's ${ }^{1}$ & 62 & 12.9 & 77 & 11.5 & 13.7 & 0.479 \\
\hline Cancer & 2 & 0.4 & 2 & 0.4 & 0.4 & 0.917 \\
\hline Physical Disability & 103 & 15.7 & 90 & 13.5 & 14.6 & 0.251 \\
\hline Hearing disability & 50 & 7.6 & 36 & 5.4 & 6.5 & 0.099 \\
\hline Visual disability & 47 & 7.2 & 53 & 7.9 & 7.5 & 0.596 \\
\hline Mobility disability & 32 & 4.9 & 30 & 4.5 & 4.7 & 0.739 \\
\hline Other disability & 3 & 0.5 & 2 & 0.3 & 0.4 & 0.640 \\
\hline Mental Health problem & 314 & 47.9 & 383 & 57.2 & 52.6 & $0.001^{*}$ \\
\hline Insecurity feeling & 106 & 16.1 & 141 & 21.1 & 35.4 & 0.384 \\
\hline Boredom feeling & 213 & 32.4 & 295 & 44.1 & 38.3 & $0.005^{\star}$ \\
\hline Loneliness & 205 & 31.2 & 294 & 43.9 & 37.6 & $0.001^{*}$ \\
\hline Anxiety/stress & 267 & 40.6 & 344 & 51.4 & 46.1 & $0.004^{*}$ \\
\hline Neglect & 98 & 14.9 & 142 & 21.2 & 18.1 & 0.099 \\
\hline Sadness/depression & 123 & 18.7 & 176 & 26.3 & 22.5 & 0.067 \\
\hline Other & 15 & 2.3 & 10 & 1.5 & 3.6 & 0.128 \\
\hline
\end{tabular}

${ }^{1}$ Self-reported but not clinically diagnosed ${ }^{\star} \mathrm{p}<0.01$. 
mentioned other health problems. The sole significant sex difference was for gastritis $(\mathrm{p}=0.002)$, more commonly reported by women.

Physical disability was reported by $14.6 \%$ of the sample. This category included visual disability (7.5\%), hearing disability (6.5\%), mobility disability $(4.7 \%)$ and other disability $(0.4 \%)$. There were no statistically significant physical disability differences between males and females.

Table 2 also shows that $52.6 \%$ of the sample of older adults reported some type of mental health problem, the most common being anxiety/stress (46.1\%), feelings of boredom (38.3\%), and loneliness (37.6\%). Compared to men, women were significantly more likely to report mental health problems in general $(\mathrm{p}=$ $0.001)$ and, specifically, for boredom $(p=0.005)$, loneliness $(p=0.001)$ and anxiety/stress $(\mathrm{p}=0.004)$.

\section{Discussion}

In Asian nations, as in much of the rest of the world, there is an inverse relationship between economic well-being and the rate of ageing [25]. Many less well-developed societies, despite the rapid growth of their older populations and perhaps due to their historical family-centered cultures, still lack a national policy focus on ageing-related issues [26] [27]. Most gerontological studies in Nepal have used small samples, and few focus on the health of the elderly. This study used a larger sample to describe the social and health status of community-dwelling older adults in Nepal.

Some results of this study are noteworthy, particularly when examining male-female differences in older adults. First, consistent with studies in different nations [28], this study found widespread widowhood (45.2\%) among those age $60+$, with significantly higher rates for females $(58.4 \%)$ than males $(31.8 \%)$. Next, literacy is low in general (30\%), but males are significantly more likely than females to be literate $(54.0 \%$ vs. $6.4 \%)$. This too reflects studies in other south Asian countries [29] [30] [31]. Third, over three-quarters of older adults in this study (78.6\%) were living with family members (yet this is low compared to previous studies [3] [10] [13] [32]). Another $11.6 \%$ lived with only their spouses and 3.5\% lived with "others". Only $6.2 \%$ of the sample was living alone; this can be a concern, but also is below the prevalence found by other research [13]. Finally, only $9.2 \%$ of the older adults in this study received a pension, with males significantly more likely than females to enjoy this economic support.

These findings can be explained by the historical evolution of Nepalese society, culture, economics and politics. First, as in other cultures, Nepali men typically marry women younger than themselves and, if widowed or divorced, are more likely to remarry [10]. A 2011 census found the age at first marriage was 22.1 years for males vs. 17.9 years for females [9]. Next, while overall adult literacy in Nepal is over 50\% [33], there are still sex-based differences: male literacy is $71.6 \%$ compared to females' $44.5 \%$. Given the increase in literacy over time and the continued male-female differences, it is not surprising that the older 
cohorts in this study had both lower literacy than the overall adult population and greater sex-based differences.

Literacy is of course linked to educational attainment; in Nepal a higher percent of men than women complete every level of education above primary school [34]. Educational attainment is linked to occupational status, and higher occupational status can be related to the likelihood and level of a pension. Given these trends in Nepal, it is not surprising that older males are significantly more likely than older females to receive a pension.

In Nepali culture, living with family members has historically been regarded as the best insurance for old age [10] [24] [28], as there was no well-developed social security system [7] [16]. This changed only in late 2018 [35] when the government announced such a program to cover workers in the formal sector and, in the future, the informal sector. Over $90 \%$ of the program's revenues are targeted for old-age economic security. In this study, the major reasons given for living alone were no support from children, no children, children living in other areas, and death of a spouse. A few respondents said they lived alone because they chose to, despite other options.

Regarding self-reported health status of community-dwelling Nepalese elderly, this study found over three-quarters $(76.5 \%)$ of older adults with some physical health problem, over half (52.6\%) with some mental health problem, and $14.6 \%$ with some physical disability. Nepalese women were significantly more likely than men to report physical and mental health problems. This is consistent with other studies in Nepal [3] [10] [13] [15] [17] that showed high rates of chronic disease [14] [32], functional disability [32] [36], depression [37] [38] and loneliness [27] among older adults. In the current study, significant sex-based differences were found for gastritis, boredom, loneliness and anxiety/stress, with females more likely to report these conditions. Women are twice as likely as men to be diagnosed with a mental illness and more likely than men to have been treated, especially for conditions like depression and anxiety [39]. Gender-based social inequality is strongly associated with gender disparities in mental health [39].

Overall, although older adults in many South Asian countries contend with similar health problems, the health status of Nepalese community-dwelling older adults seems worse when the data are compared with other research [29] [30] [31] [40] [41] [42] [43]. It also seems clear that while sex-based biological and psychological differences account for some physical and mental health differences, reducing gender-based inequality in education, the workplace and health care access and treatment would be a substantial step toward narrowing the health gap between males and females.

This study is not free from limitations. The cross-sectional nature of this study is a limitation, as in all such studies, regarding the ability to test causal relationships between variables. The original CDPS study [23] included qualitative data, focus group data, case studies and key informant interviews, which made a larg- 
er and more representative sample prohibitively expensive for CDPS. Nonetheless, analysis of the qualitative data will complement the quantitative findings, and may yield entirely new insights. Since this study was conducted in one area of Kathmandu, replication with larger, probability-based samples in other urban and, especially, rural areas of Nepal could assess the generalizability of this study's findings, pinpointing differential needs based on geography, community size and their correlates (e.g. income, education). Likely future changes in Nepali social structure include a growth of institutional residential care for older adults; these populations can also be studied. Additional research could employ a longitudinal design, especially given the considerable period and cohort differences in Nepal due to rapid social, cultural, political and economic change. Additional variables and follow-up, in-depth interviews with a subset of respondents would shed more light on the physical and mental health of older adults. Including measures of happiness or life satisfaction [44] [45] would yield knowledge about the relationship of health to quality of life among Nepalese elderly.

In this exploratory and descriptive associational analysis of secondary data, there are three final limitations. First, since most variables were measured at nominal or ordinal levels, more powerful measures of statistical significance could not be used. Second, neither the social status nor the health status of older adults was measured with any single dependent variable. Lastly, the reliability and validity of self-reported data must always be considered. Future research should employ multivariate analysis of a database of sociodemographic and health variables measured at interval or ratio levels, and a global measure of health status; these changes would make explanatory findings more likely.

\section{Conclusions}

Like many other developing nations, Nepal is experiencing the rapid growth of its elderly population that accompanies the demographic transition. As Nepal continues its modernization, social and economic changes occur that have consequences for Nepal as a society but particularly for Nepalese families-their structure, their intergenerational relationships, and their financial and health security.

In addition, among older Nepalese there are significant gender differences in marital status, living arrangements, literacy, pensions, overall physical health and overall mental health. In any society, such differences typically result from a culture that historically engaged in sex-based discrimination against women. While it is likely that gender disparities will decrease as Nepal continues its modernization, the disparities among the older population will largely persist, since few of them can be significantly addressed at this late stage in older cohorts' lives. However, some positive steps could benefit all generations as quickly as they can be implemented. It is recommended that the government continue to develop age-appropriate policies and programs to promote physical and mental health and to enhance overall quality of life among Nepalese elderly. 


\section{Acknowledgements}

We thank the Central Department of Population Studies, Tribhuvan University, Nepal for providing the database for this research.

\section{Declarations}

\section{Ethics Approval and Consent to Participate}

This study was approved by the Nepal Health Research Council (Ref No. 211, Reg No. 66/2012) as conforming to ethical research standards. Training for the thirteen field researchers/surveyors included not only research ethics such as voluntary participation, informed consent and identity protection, but also techniques for effectively interviewing older persons. It was emphasized that elderly respondents be treated with respect, dignity and honor. Direct or indirect discrimination based on age, gender, social and economic class, disability/health status, and residence during the interview process would not be tolerated. For each participant, verbal informed consent was obtained before beginning the interview.

\section{Consent for Publication}

Participants gave informed consent prior to being interviewed. No identifying information was collected. No details, images, or videos relating to an individual person were collected. Results are reported in the aggregate.

\section{Availability of Data and Material}

The dataset used and/or analyzed during the current study is available from the corresponding author on reasonable request.

\section{Funding}

No funding was received for this research.

\section{Authors' Contributions}

HNC obtained the data for this article from the Central Department of Population Studies, Tribhuvan University, Nepal. Both authors participated in data analysis and interpretation. HNC drafted the manuscript. ER revised it. Both authors read and approved the final version. Both authors confirm that the content has not been published elsewhere and does not overlap or duplicate their previously published work.

\section{Conflicts of Interest}

The authors declare that they have no competing interests.

\section{References}

[1] The Lancet (2014) Global Elderly Care in Crisis. The Lancet, 383, 927. https://doi.org/10.1016/S0140-6736(14)60463-3 
[2] Kudo, S., Mutisya, E. and Nagao, M. (2015) Population Aging: An Emerging Research Agenda for Sustainable Development. Social Sciences, 4, 940-966. https://doi.org/10.3390/socsci4040940

[3] Chalise, H.N., Saito, T., Takahashi, M. and Kai, I. (2007) Relationship Specialization amongst Sources and Receivers of Social Support and Its Correlations with Loneliness and Subjective Well-Being: A Cross Sectional Study of Nepalese Older Adults. Archives of Gerontology and Geriatrics, 44, 299-314.

[4] Lloyd-Sherlock, P. (2000) Population Ageing in Developed and Developing Regions: Implications for Health Policy. Social Science \& Medicine, 51, 887-895. https://doi.org/10.1016/S0277-9536(00)00068-X

[5] World Health Organization (2018) Aging and Health. https://www.who.int/news-room/fact-sheets/detail/ageing-and-health

[6] Wang, D., Zheng, J., Kurosawa, M., Inaba, Y. and Kato, N. (2009) Changes in Activities of Daily Living (ADL) among Elderly Chinese by Marital Status, Living Arrangement, and Availability of Healthcare over a 3-Year Period. Environmental Health and Preventive Medicine, 14, 128-141.

https://doi.org/10.1007/s12199-008-0072-7

[7] Chalise, H.N. (2006) Demographic Situation of Population Ageing in Nepal. Kathmandu University Medical Journal, 4, 354-362.

[8] Nepal Law Commission, Government of Nepal (2006) Senior Citizens Act 2063. http://www.lawcommission.gov.np/en/archives/19011

[9] Central Bureau of Statistics (2014) Population Monograph of Nepal 2014 Volume I: Demographic Analysis. National Planning Commission Secretariat, Government of Nepal, Kathmandu.

https://nepal.unfpa.org/en/publications/population-monograph-nepal-2014-volume -i-demographic-analysis

[10] Chalise, H. and Brightman, J. (2006) Aging Trend: Population Aging in Nepal. Geriatrics \& Gerontology International, 6, 199-204. https://doi.org/10.1111/j.1447-0594.2006.00347.x

[11] World Population Data Sheet (2018) Population Reference Bureau, USA. https://www.prb.org/wp-content/uploads/2018/08/2018_WPDS.pdf

[12] Mishra, S. and Chalise, H.N. (2019) Health Status of Elderly Living in Briddaashram (Old Age Home). International Journal of Public Health and Safety, 4, 172. https://www.omicsonline.org/open-access/health-status-of-elderly-living-in-briddaa shram-old-age-home-107389.html

[13] Chalise, H.N. and Shreshta, S. (2005) Situation of the Elderly in the Himalayan Kingdom of Nepal. Indian Journal of Social Work, 66, 136-143.

[14] Bhatta, R. (2009) Social and Health Status of Elderly Population in Far-Western Region. A Research Report Submitted to Nepal Health Research Council. http://library.nhrc.gov.np:8080/nhrc/bitstream/handle/123456789/42/558.pdf?seque $\underline{\text { nce }=1}$

[15] Chalise, H.N. and Basnet, M. (2017) Abuse of Older Adults Residing in the Community of Nepal. Journal of Gerontology \& Geriatric Research, 6, 415. https://doi.org/10.4172/2167-7182.1000415

[16] Malakar, I. and Chalise, H.N. (2019) Perception of Elderly towards Social Security Allowance in Nepal. South Asian Journal of Social Studies and Economics, 2, 1-9. https://doi.org/10.9734/sajsse/2018/v2i430008 http://www.journalsajsse.com/index.php/SAJSSE/article/view/30008 
[17] Rai, S., Khanal, P. and Chalise, H.N. (2018) Elderly Abuse Experienced by Older Adults Prior to Living in Old Age Homes in Kathmandu. Journal of Gerontology \& Geriatric Research, 7, 460. https://doi.org/10.4172/2167-7182.1000460

[18] Khanal, P., Rai, S. and Chalise, H.N. (2018) Children's Migration and Its Effect on Elderly People: A Study at Old Age Homes in Kathmandu. American Journal of Gerontology and Geriatrics, 1, 1-6.

http://www.remedypublications.com/american-journal-of-gerontology-and-geriatri cs/articles/pdfs_folder/ajgg-v1-id1001.pdf

[19] Ostan, R., Monti, D., Gueresi, P., Bussolotto, M., Franceschi, C. and Baggio, G. (2016) Gender, Aging and Longevity in Humans: An Update of an Intriguing/Neglected Scenario Paving the Way to a Gender-Specific Medicine. Clinical Science, 130, 1711-1725. https://doi.org/10.1042/CS20160004

[20] Nagaratnam, N. (2019) Ageing and Longevity. In: Nagaratnam, N., Nagaratnam, K. and Cheuk, G., Eds., Advanced Age Geriatric Care, Springer, New York.

[21] World Health Organization (2019) Gender and Ageing. https://www.who.int/ageing/gender/en/

[22] World Health Organization (2011) Global Health and Aging. http://www.who.int/ageing/publications/global_health.pdf

[23] Bisht, P.S., Pathak, R.S., Subedi, G., Shakya, D.V. and Gautam, K.M. (2012) Health and Social Care Needs Assessment of Elderly: The Context of Piloting Service Developments and Care of Elderly in Pharping, Kathmandu, Nepal. Tribhuvan University, Ageing Nepal, Kathmandu, Nepal and United Nations Population Fund. https://www.ifa-fiv.org/wp-content/uploads/2012/12/ReportElderlyNepal.pdf

[24] Central Bureau of Statistics (2011) National Population and Housing Census. http://mofald.gov.np/mofald/userfiles/docs_206.pdf

[25] Holmes, W.R. and Joseph, J. (2011) Social Participation and Healthy Ageing: A Neglected, Significant Protective Factor for Chronic Non-Communicable Conditions. Globalization and Health, 7, 43. https://doi.org/10.1186/1744-8603-7-43

[26] Shrestha, L.B. (2000) Population Ageing in Developing Countries. Health Affairs, 19, 204-212. https://doi.org/10.1377/hlthaff.19.3.204

[27] Chalise, H.N. (2010) Social Support and Its Correlation to Loneliness and Subjective Well-Being of Nepalese Older Adults. Asian Social Work and Policy Review, 4, 1-25. https://doi.org/10.1111/j.1753-1411.2009.00034.x

[28] Dhar, H.L. (2001) Gender, Aging, Health and Society. Journal of the Association of Physicians of India, 49, 1012-1020.

[29] Saeed, Y., Shoaib, M. and Ilyas, R. (2011) Discrimination and Health Status of Elderly People in Chakwal, Pakistan. Academic Research International, 1, 149-155. http://www.savap.org.pk/journals/ARInt./Vol.1(3)/2011(1.3-16).pdf

[30] Kamble, S.V., Ghodke, Y.D., Dhumale, G.B., Avchat, S.S. and Goyal, R.C. (2012) Health Status of Elderly Persons in Rural Area of India. Indian Medical Gazette, 295-299.

[31] Hosain, G.M. and Begum, A. (2003) Health Needs and Health Status of the Elderly in Rural Bangladesh. Asia Pacific Journal of Public Health, 15, 3-9. https://doi.org/10.1177/101053950301500102

[32] Chalise, H.N. (2012) Socio-Demographic and Health Status of Nepalese Elderly. Indian Journal of Gerontology, 26, 151-160.

[33] Aryal, S. (2014) Women and the Education System in Nepal. https://iversity.org/blog/women-education-system-nepal 
[34] Nepal-Educational Attainment, Some Primary, Population 25+ Years, Male. https://tradingeconomics.com/nepal/educational-attainment-some-primary-popula tion-25-years-male-percent-wb-data.html

[35] ILO (2018) Nepal Launches Contribution-Based Social Security Scheme. International Labour Organization, UN.

https://www.ilo.org/kathmandu/info/public/pr/WCMS_651182/lang--en/index.htm

[36] Chalise, H.N., Saito, T. and Kai, I. (2008) Functional Disability in Activities of Daily Living and Instrumental Activities of Daily Living among Nepalese Newar Elderly. Public Health, 122, 394-396. https://doi.org/10.1016/j.puhe.2007.07.015

[37] Chalise, H.N. (2014) Depression among Elderly Living in Briddashram (Old Age Home). Advances in Aging Research, 3, 6-11.

https://doi.org/10.4236/aar.2014.31002

[38] Thapa, D.K., Visentin, D., Kornhaber, R. and Cleary, M. (2018) Prevalence of Mental Disorders among Older People in Nepal: A Systematic Review. Kathmandu University Medical Journal, 62, 181-190.

[39] Yu, S. (2018) Uncovering the Hidden Impacts of Inequality on Mental Health: A Global Study. Translational Psychiatry, 8, 98.

https://doi.org/10.1038/s41398-018-0148-0

[40] Ghosh, A. and Singh, A. (2014) Health Status of Elderly in a Rural Area of North East Region of India. National Journal of Community Medicine, 5, 236-239. http://njcmindia.org/uploads/5-2_236-239.pdf

[41] Sherina, M.S., Rozali, A., Shiran, M.S. and Sam, A.A. (2004) The Association of Nutritional Risk with Physical and Mental Health Problems among Elderly in a Semi-Urban Area of Mukim Kajang, Selangor, Malaysia. Malaysian Journal of $\mathrm{Nu}$ trition, 10, 149-158.

[42] Beard, J.R., Officer, A., de Carvalho, I.A., Sadana, R., Pot, A.M., Michel, J.P., et al. (2015) The World Report on Ageing and Health: A Policy Framework for Healthy Ageing. The Lancet, 387, 2145-2154. https://doi.org/10.1016/S0140-6736(15)00516-4

[43] Wasnik, V.R. and Jawarkar, A.K. (2015) A Community-Based Study to Assess the Morbidity Profile of the Geriatric Population in a Rural Area of Amravati District of Maharashtra, India. International Journal of Health Sciences and Research, 5, 25-31.

[44] Poon, L. and Cohen-Mansfield, J. (2011) Understanding Well-Being in the Oldest Old. Cambridge University Press, Cambridge. https://doi.org/10.1017/CBO9780511920974

[45] Pavot, W. and Diener, E. (1993) Review of the Satisfaction with Life Scale. Psychological Assessment, 5, 164-172. https://doi.org/10.1037/1040-3590.5.2.164

\author{
Abbreviations \\ CDPS: Central Depart of Population Studies \\ PSUs: Primary Sampling Units \\ TU: Tribhuvan University \\ VDC: Village Development Committee
}

